\title{
OS SELOS AMBIENTAIS E A MODESTA CONSCIENTIZAÇÃO DOS CONSUMIDORES DO MUNICÍPIO DE BARRA DO GARÇAS - MATO GROSSO.
}

Marcel Carlos Lopes Félix ${ }^{1}$ Vanessa Ferreira de Souza ${ }^{2}$

\section{RESUMO}

Com o aumento da população mundial, a crise ambiental toma forma complexa, devido ao mal uso dos recursos naturais esgotáveis. Diante disso, os Selos Ambientais surgiram para divulgar as práticas para com o meio ambiente e informar aos consumidores acerca do processo produtivo. Nesse passo, o objetivo da pesquisa foi verificar o nível de informação dos consumidores a respeito dos Selos Ambientais na cidade de Barra do Garças, Mato Grosso, em outubro de 2017. Foi realizada pesquisa de campo e bibliográfica, adotado o método hipotético-dedutivo e analisados os dados por amostragem.

Palavras-chave: Globalização; Crise ambiental; Selos Ambientais; Informação; Consumidor consciente.

\section{THE ENVIRONMENTAL SEALS AND THE CONSUMERS OF THE MUNICIPALITY OF BARRA DO GARÇAS - MATO GROSSO'S MODEST CONSENT.}

\begin{abstract}
With the increase of the world population, the environmental crisis takes on a complex form, due to the misuse of the exhaustible natural resources. Therefore, Environmental Seals appeared to disseminate practices towards the environment and inform consumers about the production process. In this step, the objective of the research was to verify the level of consumer information regarding Environmental Seals in the city of Barra do Garças, Mato Grosso, in October 2017. Field and bibliographical research was done, adopting the hypothetical-deductive method and analyzed the data by sampling.
\end{abstract}

Keywords: Globalization; Environmental crisis; Environmental Seals; Information; Conscious consumer.

\section{INTRODUÇÃO E OBJETIVOS}

A população encontra-se em constante crescimento e vem contribuindo para a geração de perturbações no equilíbrio ambiental (KOHLRAUSCH, 2003, p. 14). As intensas atividades cotidianas das populações do mundo globalizado proporcionam uma escassez de

\footnotetext{
1 Doutorando em Direito pelo Uniceub - Brasília/DF. Mestre em Direito, Relações Internacionais e Desenvolvimento pela PUC/GO. Pós-graduado em Direito Empresarial pela Universidade Federal de Mato Grosso, em Direito e Processo do Trabalho pela Anhanguera-Uniderp-Luís Flávio Gomes e em Docência no Ensino Superior pelas Faculdades Cathedral. Docente na Universidade Federal de Mato Grosso. Contato: marcel-felix@uol.com.br.

${ }^{2}$ Pós-graduada em Gestão e Planejamento Ambiental pela Universidade Federal de Mato Grosso e Graduada em Agronomia pela Universidade Federal de Mato Grosso. Contato: vfb_vanessa@ hotmail.com.
}

Revista de Direito e Sustentabilidade | e-ISSN: 2525-9687 | Salvador | v. 4 | n. 1 | p. 110 - 129 | Jan/Jun. 
tempo para realizarem compras em supermercados, além disto, a mídia aliena os consumidores a adquirirem produtos com maior frequência (GRUETZMANN, 2015, p. 08).

Para suprir as necessidades da população acelerada, o homem é visto como agente modificador do meio em que vive e participa do processo exploratório da natureza, fazendo o uso indevido dos recursos naturais, aumentando a produção e emissão de poluentes e financiando um sistema de produção que vai contra os princípios do desenvolvimento sustentável (KOHLRAUSCH, 2003, p. 18).

Com isso, a ambição do ser humano na busca por sua expansão territorial e do conhecimento científico, contribui para o aumento dessas crises. A medida em que essa sociedade se desenvolve, passo a passo, faz surgir as "sociedades de consumo" altamente consumistas, passando a agir sem calcular riscos e prejuízos sobre o meio ambiente e a própria sociedade (CANDEMIL, 2012, p. 21).

No entanto, devido à implementação das técnicas de produção e o consumo exacerbado, advindos da Revolução Industrial, surgiram grandes impactos ao meio ambiente e, no decorrer dos anos, o homem tornou-se um agente de degradação ambiental. Seu modo de vida altamente capitalista foi um dos responsáveis pela crise, a qual é medida em escala global, significando que as ações que pratica acabam afetando outros lugares do planeta (KOHLRAUSCH, 2003, p. 52).

A partir de 1962, com a publicação da obra "Primavera silenciosa", de Rachel Carson, ganhou destaque a preocupação de consumir de forma mais sustentável e ao mesmo tempo preservando o planeta das ações desumanas (DEUS et. al., 2010, p. 03). Os Selos ambientais surgiram da pressão que a população gerou sobre as empresas, devido à exigência de utilizar produtos e serviços ditos como ambientalmente sustentáveis. Os Selos ambientais tornaram-se um critério de escolha, disponibilizados aos consumidores no momento de realizarem suas compras (BARBIERI, 2008, p. 102).

Diante da falta de informações suficientes, apresenta-se a problemática desta pesquisa, no sentido de saber se os consumidores, atualmente, buscam produtos que contenham Selos ambientais.

Nesse passo, a hipótese admitida, inicialmente, foi de que os consumidores não verificam os Selos ambientais ao fazer a aquisição dos produtos, ou se pesquisam, ainda não tomam como critério de escolha de produtos, a existência de um Selo ambiental.

O consumidor vincula seu conhecimento em percepções e crenças que estão relacionadas às vendas e às negociações, porém, sua decisão de compra deveria basear-se na 
relação com o meio ambiente e com as transformações econômicas. O estudo da percepção do consumidor é necessário para que ele tenha um comportamento de acordo com as questões de sustentabilidade e ao mesmo tempo buscando incentivar as empresas a investirem em estratégias de sustentabilidade para disponibilizar produtos que atendam às expectativas destes consumidores (DEUS et. al., 2010, p. 35).

Com o surgimento da "onda verde", várias bandeiras foram levantadas em favor das questões ambientais. Este movimento ganha força diante da preocupação dos consumidores com a preservação do meio ambiente e a busca em saber se as empresas têm utilizado, em seu sistema de produção, metodologias que buscam minimizar os impactos ambientais como, por exemplo, a produção mais limpa (KOHLRAUSCH, 2003, p. 16).

Com isso, a medida em que as empresas cumpram as exigências dos programas relacionados aos Selos Ambientais, essas podem fazer uso dos Selos verdes nos rótulos de seus produtos. O principal motivo que leva as empresas a utilizarem os Selos verdes em seus produtos é devido à pressão feita por uma parcela dos consumidores cada vez mais exigente e preocupados com as questões ambientais. No entanto, grande parte dos consumidores adquirem os produtos e serviços, todavia, não sabem como foram produzidos e se causam muito impacto negativo ao meio ambiente ou não, seja ele durante o processo produtivo com a extração de matéria-prima, no processo industrial, no transporte ou mesmo no processo de descarte das embalagens e produtos (PREUSSLER et. al., 2006, p. 03).

No Brasil, os Selos verdes são atribuídos aos produtos por intermédio das normas contidas na Associação Brasileira de Normas Técnicas (ABNT), mediante a série ISO 14020 (International Organization for Standardization), a qual orienta a criação dos Selos e das declarações ambientais (ABNT, 2002, on line).

Nesse sentido, de acordo com o problema e hipótese desta pesquisa, justifica-se a relevância desta pesquisa, uma vez que poder-se-á descobrir qual o grau de conhecimento dos consumidores a respeito da utilização de Selos Verdes em produtos e serviços.

A presente pesquisa, então, tem como objetivo primordial levantar e analisar o grau de informação dos consumidores quanto a utilização de Selos Verde e foi delimitado o município de Barra do Garças - Mato Grosso (critério espacial), 02 (dois) Supermercados "A" E "B", sendo que o levantamento de dados foi feito no mês de novembro de 2017 (critério temporal). 
A metodologia utilizada foi a pesquisa de campo e bibliográfica, com o levantamento de dados e utilizando-se do método hipotético-dedutivo, para então fazer-se a análise por meio de Amostragem.

Entende-se que este artigo se encaixa na linha de pesquisa Direito e Sustentabilidade, uma vez que o Selo Verde trata-se de tema que envolve o tripé da Sustentabilidade: meio ambiente, transformação econômica e impactos sociais.

\section{REFERENCIAL TEÓRICO}

O crescimento mundial aumentou o número de famintos no mundo (HOLTGIMENEZ, et. al, 2006, p 4) e o capitalismo alargou a distância ditos "ricos" e "pobres". Na era do crescimento econômico, é preciso administrar os recursos naturais assegurando o progresso da humanidade (BRUNDTLAND, 1991, on line).

Desde a década de 1980, vem ganhando destaque um modelo de produção que tem como estratégia produzir bens e serviços de forma a minimizar os impactos ambientais atendendo os objetivos do desenvolvimento sustentável (OLIVEIRA, et. al., 2009, p 02). A Conferência de Estocolmo, em 1972, prevê que a produção gere menos resíduos, que lance menos poluentes no meio ambiente e que consuma menos recursos naturais. Com o surgimento dos modelos eco eficientes, é possível produzir a quantidade de materiais e energia por unidade de produto sem que ocorra o aumento dos preços para as empresas e, ao mesmo tempo, que se possa reduzir os impactos ao ambiente (BARBIERI, 2008, p. 122).

A utilização de Selos Ambientais é um instrumento de comunicação que busca informar aos consumidores a respeito das práticas de produção, para que os mesmos alterem seus padrões de consumo para uma postura mais consciente e responsável, levando-os a adquirirem produtos sustentáveis (MOURA, 2013, p. 18).

O termo Selos Ambientais, mais especificamente o selo, é tratado por várias nomenclaturas diferentes, dentre as mais utilizadas estão: eco rótulos, rótulos ambientais, rótulos ecológicos, selo verde, eco selo e etiqueta ecológica (KOHLRAUSCH et al., 2003, p. 77; NAKAHIRA \& MEDEIROS, 2009, p. 546; BIAZIN, 2002, p. 21). Independente da nomenclatura atribuída a eles, esses Selos devem ser precisos, verificáveis, relevantes e não enganosos (CAMPOS et. al., 2004, p. 04).

O primeiro país a criar um Selo Verde foi a Alemanha, em 1977, por meio da iniciativa do governo, sociedade e das igrejas. A este Selo foi atribuído o nome de Anjo Azul 
(BARROS \& FREITAS, 2010, p. 03). Diante do sucesso que foi o Selo alemão, muitos outros países criaram outros Selos e programas, conforme quadro 01.

Quadro 1. Principais selos internacionais e suas características.

\begin{tabular}{|c|c|c|c|c|}
\hline \multicolumn{5}{|c|}{ Principais Selos Internacionais e suas Características } \\
\hline Nome & Logo & País & Ano & Objetivo \\
\hline $\begin{array}{l}\text { Blue Angel } \\
\text { (Anjo Azul) }\end{array}$ & & Alemanha & 1977 & $\begin{array}{l}\text { Certificar produtos que geram menor } \\
\text { impacto ambiental, declarando } \\
\text { o compromisso com a proteção } \\
\text { ambiental. }\end{array}$ \\
\hline $\begin{array}{l}\text { Environmental } \\
\text { Choice }\end{array}$ & & Canadá & 1988 & $\begin{array}{l}\text { Assegurar ao consumidor que os } \\
\text { produtos e serviços certificados são } \\
\text { menos danosos ao meio ambiente } \\
\text { e seguem rígidas normas de } \\
\text { verificação. }\end{array}$ \\
\hline Eco Marck & & Japão & 1989 & $\begin{array}{l}\text { Certificar produtos que geram menor } \\
\text { impacto ambiental e aumentar a } \\
\text { consciência dos consumidores sobre } \\
\text { a importância dessa redução. }\end{array}$ \\
\hline $\begin{array}{l}\text { Nordic Swan } \\
\text { (Cisne Nórdico) }\end{array}$ & & $\begin{array}{l}\text { Países } \\
\text { Nórdicos }\end{array}$ & 1989 & $\begin{array}{l}\text { Certificar produtos que atendem } \\
\text { critérios ambientais, de qualidade } \\
\text { e saúde, considerando a } \\
\text { importância do livre comercio e do } \\
\text { custo\&benefício. }\end{array}$ \\
\hline Green Seal & & $\begin{array}{l}\text { Estados } \\
\text { Unidos }\end{array}$ & 1989 & $\begin{array}{l}\text { Certificar produtos e serviços que } \\
\text { seguem um padrão de critérios } \\
\text { englobando desempenho, saúde e } \\
\text { sustentabilidade. }\end{array}$ \\
\hline NF-Environnement & & França & 1991 & $\begin{array}{l}\text { Garantir ao consumidor a qualidade } \\
\text { de uso e ambiental do produto, } \\
\text { assegurando que a redução dos } \\
\text { impactos ambientais foi considerada } \\
\text { ao longo de todo o ciclo de vida do } \\
\text { produto. }\end{array}$ \\
\hline $\begin{array}{l}\text { European Union } \\
\text { Eco-Label }\end{array}$ & & Europa & 1992 & $\begin{array}{l}\text { Identificar produtos e serviços que } \\
\text { causem menos impacto ao meio } \\
\text { ambiente durante todo seu ciclo de } \\
\text { vida. }\end{array}$ \\
\hline
\end{tabular}

Fonte: http://www.ideiasustentavel.com.br/rotulos-selos-e-certificacoes-verdes-2/

\footnotetext{
Revista de Direito e Sustentabilidade | e-ISSN: 2525-9687 | Salvador | v. 4 | n. 1 | p. 110 - 129 | Jan/Jun. 
O Brasil, em 1992, teve a primeira iniciativa de criar um Selo Verde, foi quando a ABNT (Associação Brasileira de Normas Técnicas) propôs ao Instituto Brasileiro de Proteção Ambiental, após a Conferência do Rio, a implementação de um Selo Ambiental (BARROS \& FREITAS, 2010, p. 03).

A ABNT criou um Selo, ao qual utiliza como símbolo o Colibri (Figura 01) e o objetivo deste Selo é informar aos consumidores a procedência do produto. Este programa é regido pelas normas da ISO 14000 da ABNT que busca a obediência à legislação, à transparência e à acessibilidade dos consumidores às informações dos produtos, bem como do ciclo de vida, suas características funcionais, custos, aspectos comerciais, garantindo ainda a objetividade, imparcialidade e transparências das informações (NAKAHIRA \& MEDEIROS, 2009, p. 547).

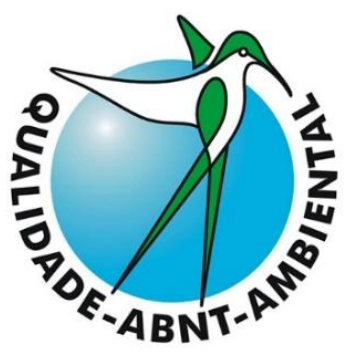

Figura 01 - Selo Ambiental da ABNT - Colibri.

Fonte: EcoD - http://vivagreen.com.br/noticias/abnt-lanca-selo-ecologico-inedito-para-eletroeletronicos/

O Selo PROCEL de economia de energia foi instituído pelo Decreto Presidencial de 08 de dezembro de 1993, e foi criado pelo Programa Nacional de Conservação de Energia Elétrica - PROCEL. Este Selo tem como objetivo principal informar ao consumidor acerca dos produtos que possuem melhor desempenho enérgico de equipamentos e eletrodomésticos dentro de cada categoria. Além disso, estimula a fabricação e comercialização de produtos que contribuam para o Desenvolvimento Sustentável, com a redução de impactos ambientais (INMETRO, 2017, online).

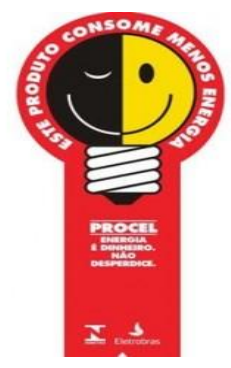

Figura 02: Selo Procel de Economia

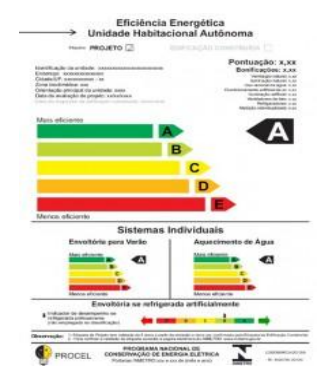

Figura 03:Etiqueta Nacional de Conservação 
O FSC (Forest Stewardship Council) é uma Organização Não Governamental criada em 1995, possui sede no México e está presente em 49 países. Surgiu da preocupação da população com a conservação ambiental e o Desenvolvimento Sustentável das florestas (WESENDONCK, 2014, p. 25). Qualquer empresa que demonstre responsabilidade na sua produção poderá receber este Selo sem custo, sendo que a taxa que é cobrada é apenas pelo acompanhamento após receber o Selo, o qual é gerado conforme o tamanho da propriedade e da renda do produtor (DEUS et al., 2010, p. 47).

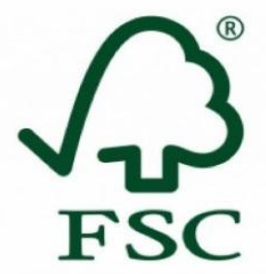

Figura 07: Selo Ambiental FSC.

Fonte: FSC- https://pt.fsc.org/pt-pt/mercados/apoio-ao-uso-da-marca/como-utilizar-as-marcas-fsc

Os selos ambientais não garantem que os produtos sejam produzidos sem que causem nenhum dano ao meio ambiente, eles apenas informam que neste processo houve menos impacto, desse modo, falar "ecologicamente correto" seria passar uma informação incorreta aos consumidores (KOHLRAUSCH et al., 2003, p. 77).

De acordo com Barros \& Freitas (2010, p. 03), existem dois tipos de Selos Ambientais. O primeiro trata-se das Auto declarações de produtos ambientais (Quadro 2) e o segundo refere-se à declaração concedida por uma instituição certificadora, conforme citado anteriormente.

A ISO é uma Federação Mundial que não possui vínculo governamental e tem como objetivo elaborar normas que buscam estabelecer concordância entre a produção em diversos países, a fim de tentar padronizar métodos e medidas utilizados em todos os tipos de atividades. São atribuídos símbolos ou expressões ao Selo do produto para facilitar o entendimento do consumidor e pode-se encontrar expressões do tipo "reciclável", "reciclado", "retornável”, "biodegradável”, dentre outros. Por sua simplicidade, as Auto declarações estão amplamente difundidas no Brasil e no mundo (NAKAHIRA, \& MEDEIROS, 2009, p. 548).

Quadro 2: Auto declarações, símbolos e logotipos. 


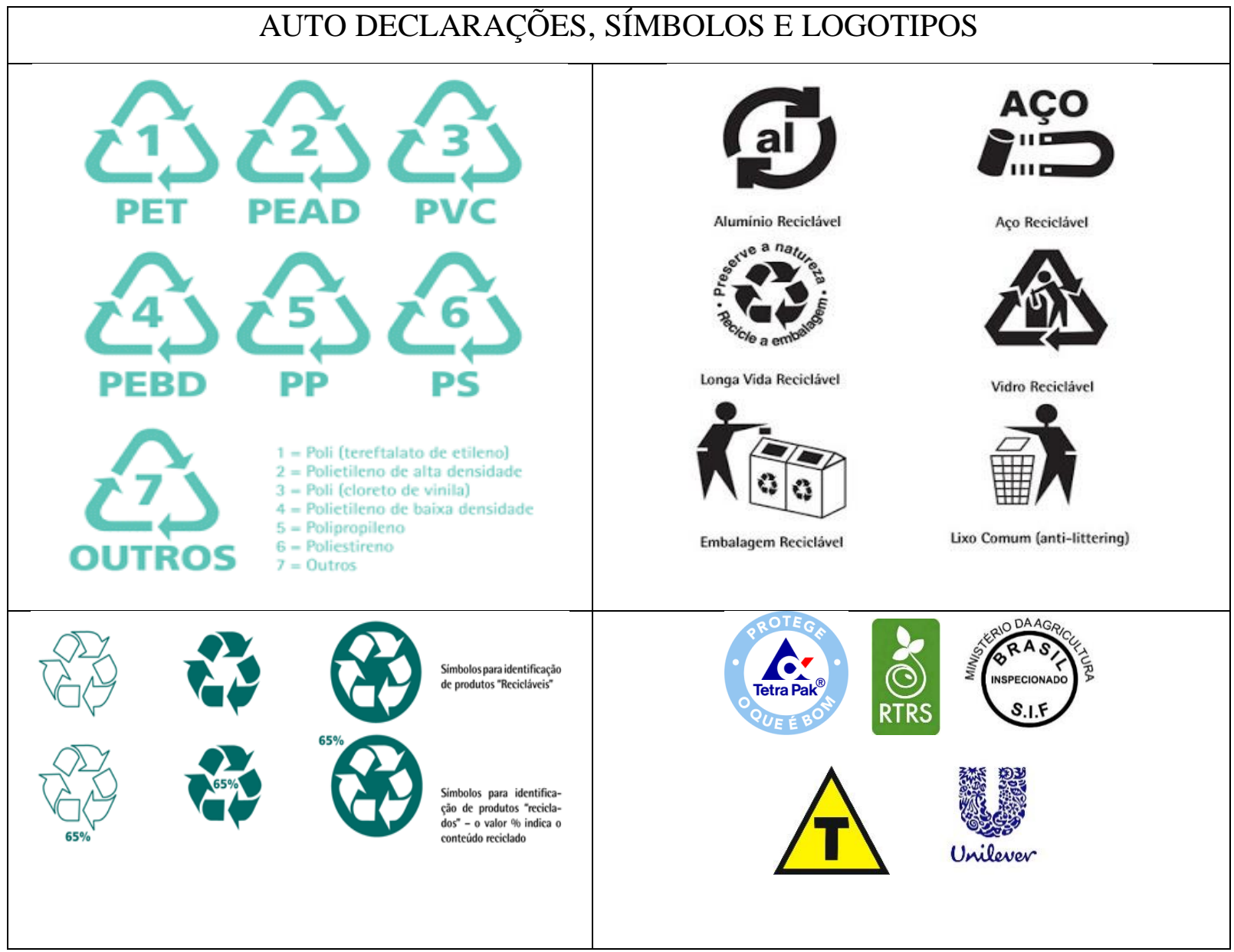

Fonte: http://embalagemsustentavel.com.br/2008/09/03/rotulagem-ambiental-i/

Dentre os tipos de Selos estabelecidos pela série ISO 14000, Preussler et al. (2006, p. 04); Biazin \& Godoy (2000, p. 09) citam:

1- $\quad$ Rotulagem tipo I - NBR ISO 14024: Programa Selo Verde. Estabelece os princípios e procedimentos para o desenvolvimento de programas de rotulagem ambiental, incluindo a seleção, critérios ambientais e características funcionais dos produtos, e para avaliar e demonstrar sua conformidade. Também estabelece os procedimentos de certificação para a concessão do rótulo.

2- $\quad$ Rotulagem Tipo II - NBR ISO 14021: Especifica os requisitos para auto declarações ambientais, incluindo textos, símbolos e gráficos, no que se refere aos produtos. Termos selecionados em declarações ambientais e fornece qualificações para seu uso.

3- Rotulagem Tipo III - ISO 14025: Inclui avaliação do ciclo de vida. Ainda está sendo elaborada no âmbito da ISO. Tem alto grau de complexidade devido à inclusão da ferramenta Avaliação do Ciclo de Vida.

O papel essencial da Selos Verdes é levar aos consumidores informações a respeito do processo de confecção do produto e informar qual impacto este processo causou ao meio ambiente (PREUSSLER et. al., 2006, p. 02). O surgimento de vários Selos Ambientais em 
diferentes países, por um lado, teve boa aceitação por parte dos consumidores, por outro lado, gerou uma grande confusão, a qual demanda a definição de normas e diretrizes para a implementação dos Selos Verdes (WESENDONCK, 2014, p. 32).

Um grande número de empresas têm buscado a postura ambientalista e aceitado as pressões dos consumidores pela preferência aos Selos, uma vez que se preocupam com sua reputação e buscam meios de proteger o Meio Ambiente, enquanto garantem seu desempenho financeiro e mercadológico (BARBIERI, 2008, p. 110). Qualquer organização poderá solicitar um serviço de Selos Ecológico por intermédio de formulário específico, de acordo com as normas da Associação Brasileira de Normas Técnicas (ABNT, 2002, on line).

Apesar de ser conhecida por uma parte do público consumidor, os Selos Ambientais não têm sido o principal critério de escolha no momento da compra e, para facilitar sua divulgação, os Selos das embalagens dos produtos devem conter informações de forma clara e objetiva para facilitar o entendimento dos consumidores a respeito dos métodos de produção do produto que está adquirindo (NAKAHIRA \& MEDEIROS, 2009, p. 548).

Com os avanços tecnológicos, houve maior acesso às informações e à participação popular de forma direta. $\mathrm{O}$ direito à informação garante que os cidadãos possam contribuir para que o meio ambiente seja protegido e preservado ao ponto que a exploração dos recursos naturais ocorra de forma mais consciente garantindo que as futuras gerações usufruam de um ambiente ecologicamente equilibrado (PEREIRA \& BITTENCOURT, 2013, p. 84).

Ao analisar todo tipo de rótulo dos produtos foram encontrados além dos Selos Ambientais e das Auto declarações, outros tipos de símbolos, como descrito a seguir.

O Serviço de Inspeção Federal, conhecido mundialmente pela sigla SIF ou S.I.F. é vinculado ao Departamento de Inspeção de Produtos de Origem Animal - DIPOA e é o responsável por assegurar a qualidade de produtos de origem animal comestíveis e não comestíveis destinados ao mercado interno e externo, bem como de produtos importados. Atualmente, o SIF tem atuação em mais de 5 mil estabelecimentos brasileiros, todos sob a supervisão do DIPOA (MAPA, 2016, on line).

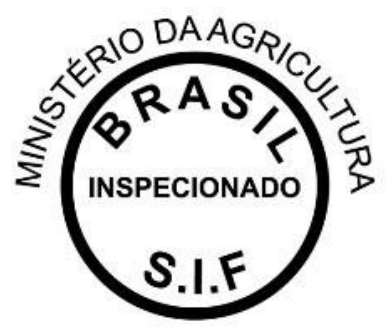


Figura 08: Símbolo S.I.F. Fonte: MAPA

O símbolo de transgênicos consiste em um triângulo amarelo com a letra "T" em seu interior e é obrigatório seu uso para de permitir que os consumidores possam identificar os produtos transgênicos. A lei que regulamenta essa obrigatoriedade é de 2003, no entanto, poucas pessoas observam a existência desse símbolo ou mesmo o reconhecem. No Decreto 4.680/2003, em seu artigo $2^{\circ}$, está disposto a respeito da obrigatoriedade do símbolo de transgênicos nos rótulos dos produtos que tivessem até 1\% de OGM (Organismos Geneticamente Modificados) em sua composição (QUARTIM, 2011, on line).

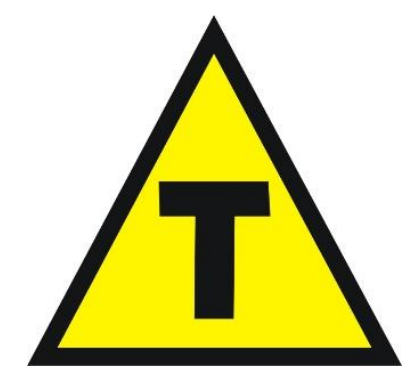

Figura 09: Símbolo Trangênico. Fonte: EMBALAGEM SUSTENTÁVEL

Muitas vezes os consumidores tendem a ficar confusos com tantas informações, ficam receosos diante de tantas falsas declarações. Devido a isso, as empresas tâm buscado formas de informar, aos consumidores, acerca dos processos produtivos de seus produtos e é dever dos consumidores buscarem essas informações para não serem lesados ou prejudicados de quaisquer formas.

Nessa esteira, tem-se como referencial teórico para realização desta pesquisa os Selos e definições acima mencionados.

\section{METODOLOGIA}

O método científico utilizado, segundo Marconi e Lakatos (2010, p. 95), foi o método hipotético-dedutivo, o qual consiste na construção de conjecturas baseada em, no mínimo, uma hipótese e possuem como etapas o reconhecimento dos fatos, definição do problema, construção de um modelo teórico, elaboração de dados e comparação das conclusões.

Este trabalho foi realizado na cidade de Barra do Garças - MT e foi realizada pesquisa de campo em dois supermercados na cidade, o Supermercado "A" e o Supermercado "B", para a verificação da existência de Selos Ambientais em alguns produtos pré- 
determinados. Em ambos, analisou-se produtos de marcas variadas e alguns deles analisou-se, aleatoriamente e por amostragem, para constar nos resultados deste trabalho.

Foi realizada, também, pesquisa de campo, mediante aplicação de questionário para um grupo de consumidores. A amostra consistiu de cinquenta pessoas entrevistadas por meio do preenchimento de questionário com oito perguntas de múltipla escolha, para verificar o grau de conhecimento destas pessoas a respeito dos Selos Verdes.

Após a realização das pesquisas, os dados obtidos foram transferidos para gráficos e tabelas e, posteriormente, realizou-se discussão dos resultados pelo método hipotéticodedutivo. Isso tudo, com a utilização da pesquisa bibliográfica, baseada em livros, artigos e textos a respeito do tema proposto para a pesquisa.

\section{DESENVOLVIMENTO DA PESQUISA, RESULTADOS E DISCUSSÕES}

O Código de Defesa do consumidor em seu artigo $6^{\circ}$, III, dispõe que:

\footnotetext{
São direitos básicos do Consumidor: a informação adequada e clara sobre os diferentes produtos e serviços, com especificação correta de quantidade, características, composição, qualidade, tributos incidentes e preço, bem como sobre os riscos que apresentem (BRASIL, 1988, on line).
}

Desse modo, os produtos e serviços disponíveis, devem, obrigatoriamente, conter informações claras e precisas disponibilizadas pelos fornecedores, bem como informar todos os riscos que possam decorrer do consumo daquele produto.

Essas informações possibilitam mais informações aos consumidores acerca dos produtos que irão consumir, deixando ao seu critério a escolha do produto. Assim, as empresas utilizam-se o Selo do produto como mecanismo intermediário entre o produto e a escolha do consumidor (GRUETZMANN, 2015, p. 21).

A partir do objetivo proposto foi possível descrever e identificar nos produtos analisados a existência de Selos Ambientais e as Auto declarações ambientais e demonstrar sua tendência de influenciar na decisão no momento da compra por parte dos consumidores.

As visitas aos supermercados tiveram a finalidade de verificar e caracterizar a existência de Selos Ambientais em alguns produtos que fazem parte do consumo dos moradores da cidade de Barra do Garças-MT. A lista de produtos analisados, bem como os Selos e Auto declarações verificados, podem ser observados no Anexo 1 deste trabalho. 
Realizou-se visitas a dois supermercados na cidade, tendo como foco dez produtos (Anexo 1). Em alguns deles foram feitas comparações entre marcas e em seguida os Selos e Auto declarações encontrados foram descritos.

Por meio das entrevistas (Apêndice 1) foi possível verificar o grau de informação dos consumidores barra-garcenses em relação aos Selos Verdes e também o poder de influência destes Selos em seu poder de compra.

Para que fosse possível identificar, de forma sintetizada, se existe alto grau de informação e preocupação dos consumidores com as questões ambientais e sua decisão em adquirir produtos ditos como "ambientalmente corretos", elaborou-se oito questões.

A primeira pergunta buscou identificar a frequência com que os consumidores pesquisados frequentavam os supermercados para fazer suas compras. Verificou-se que $46 \%$ dos consumidores frequentam os supermercados semanalmente, $28 \%$ quinzenalmente e $26 \%$ vão aos supermercados mensalmente (Figura 12).

Figura 12. Frequência dos consumidores nos supermercados. Barra do Garças-MT, 2017.

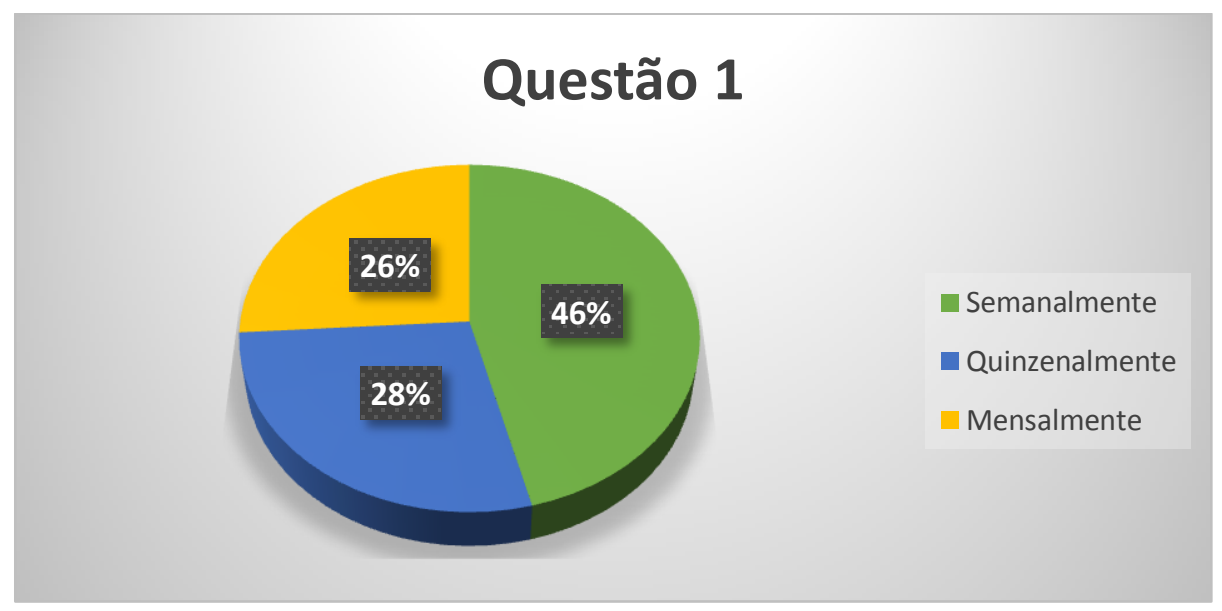

Fonte: Autores.

Na segunda questão, buscou-se analisar qual o critério de escolha dos consumidores ao adquirir os produtos. Verificou-se que $46 \%$ dos consumidores escolhem os produtos pela qualidade, $42 \%$ escolhem pelo preço e $12 \%$ escolhem os produtos pela marca (Figura 13).

Figura 13. Critério de escolha dos produtos. Barra do Garças-MT, 2017. 


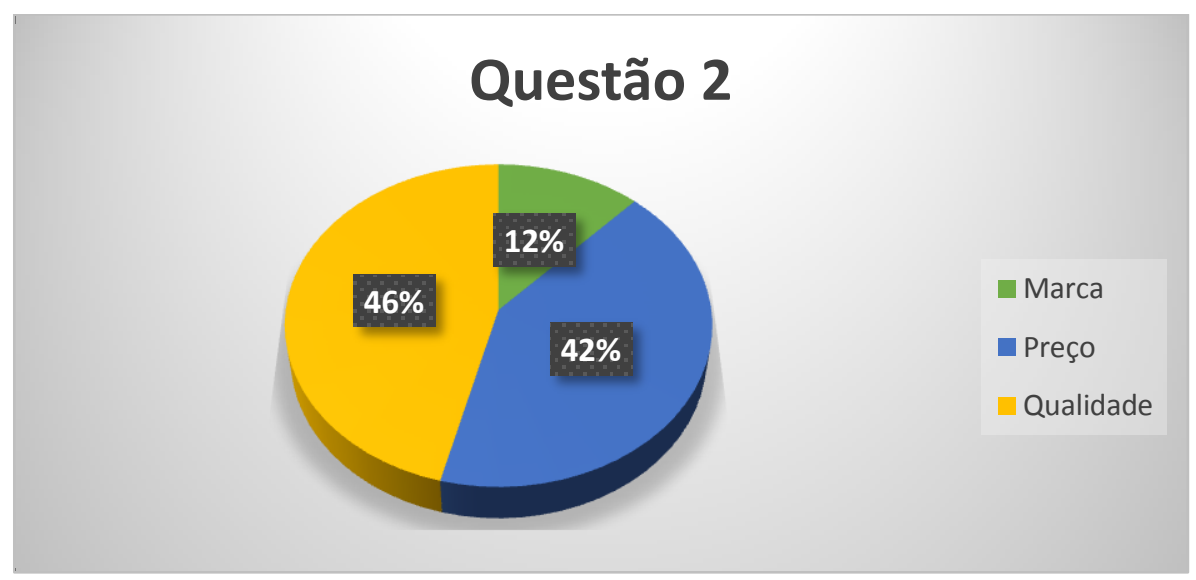

Fonte: Autores.

A terceira questão buscou verificar o que mais chama a atenção dos consumidores ao analisar os Selos dos produtos. Verificou-se que $79 \%$ dos consumidores pesquisados observam as informações nutricionais, $17 \%$ observam os símbolos contidos nos Selos e 4\% não tem resposta (Figura 14).

A apresentação da tabela de informação nutricional possibilita que o consumidor tenha a informação da quantidade de cada substância ingerida, possibilitando-o acompanhálas e permitindo que tenha uma dieta balanceada (GRUETZMANN, 2015, p. 43).

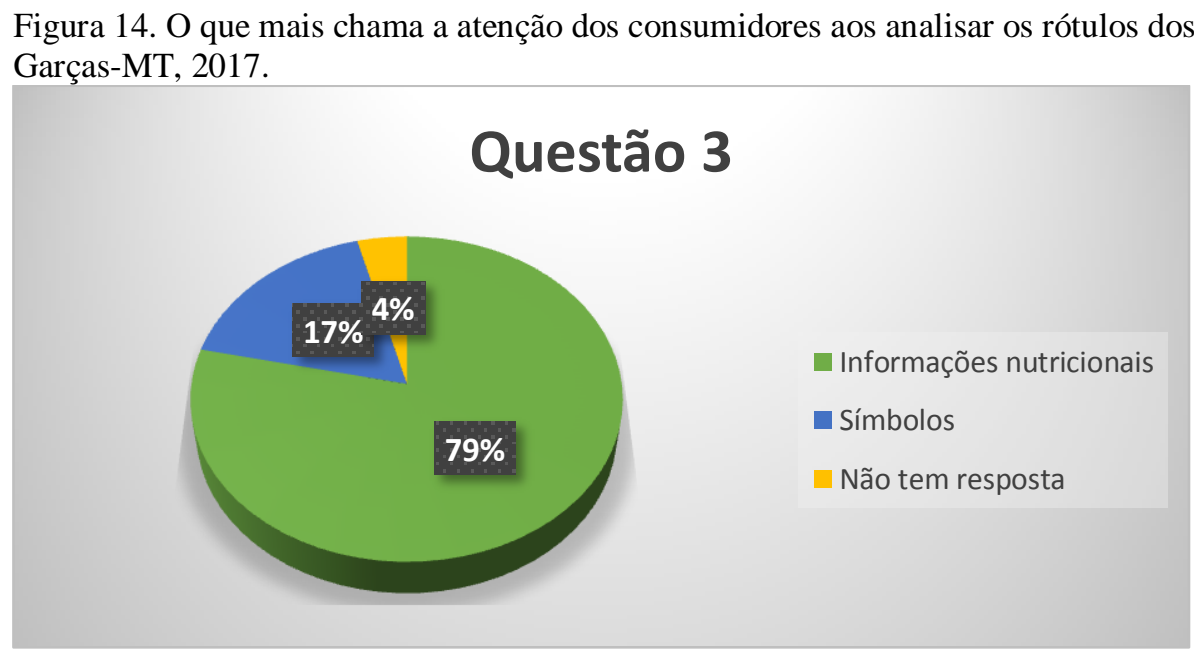

Fonte: Autores.

$\mathrm{Na}$ questão 4, o objetivo foi saber se os consumidores pesquisados tinham conhecimento de alguma etapa do processo produtivo dos produtos que adquiriam. Verificouse que $56 \%$ dos consumidores não tinham conhecimento de nenhuma etapa do processo 
produtivo dos produtos, $41 \%$ possuíam algum conhecimento e $3 \%$ não souberam responder (Figura 15).

Teixeira (2009, on line) afirma que o consumo é a razão pela qual os bens são produzidos e neste processo de consumo é que se geram as degradações. Portanto, é necessário que os consumidores entendam os processos produtivos dos produtos e sua responsabilidade no processo de degradação.

Figura 15. Conhecimento sobre alguma etapa do processo produtivo dos produtos adquiridos. Barra do Garças-MT, 2017.

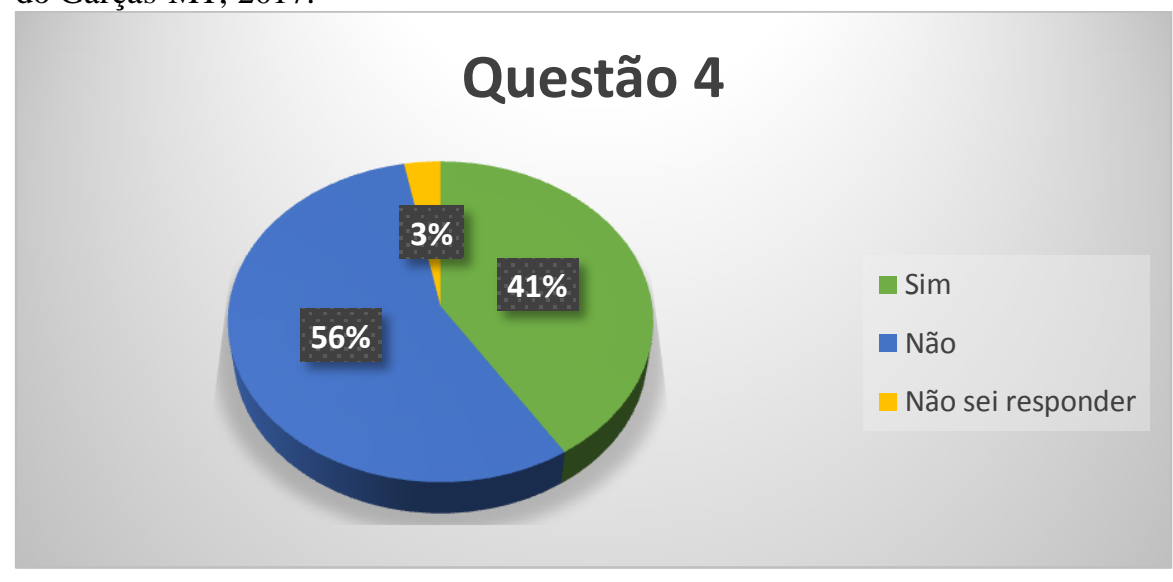

Fonte: Autores.

Com a intenção de saber se os consumidores pesquisados tinham o hábito de ler as informações contidas nos Selos das embalagens dos produtos adquiridos, a questão cinco apresentou os seguintes resultados conforme mostra a figura 16.

Verificou-se que $54 \%$ dos consumidores leem algumas vezes as informações dos Selos, $34 \%$ sempre leem as informações e apenas $12 \%$ não leem as informações contidas nos Selos das embalagens.

Figura 16. Hábito de leitura das informações contidas nos rótulos dos produtos. Barra do Garças-MT, 2017. 


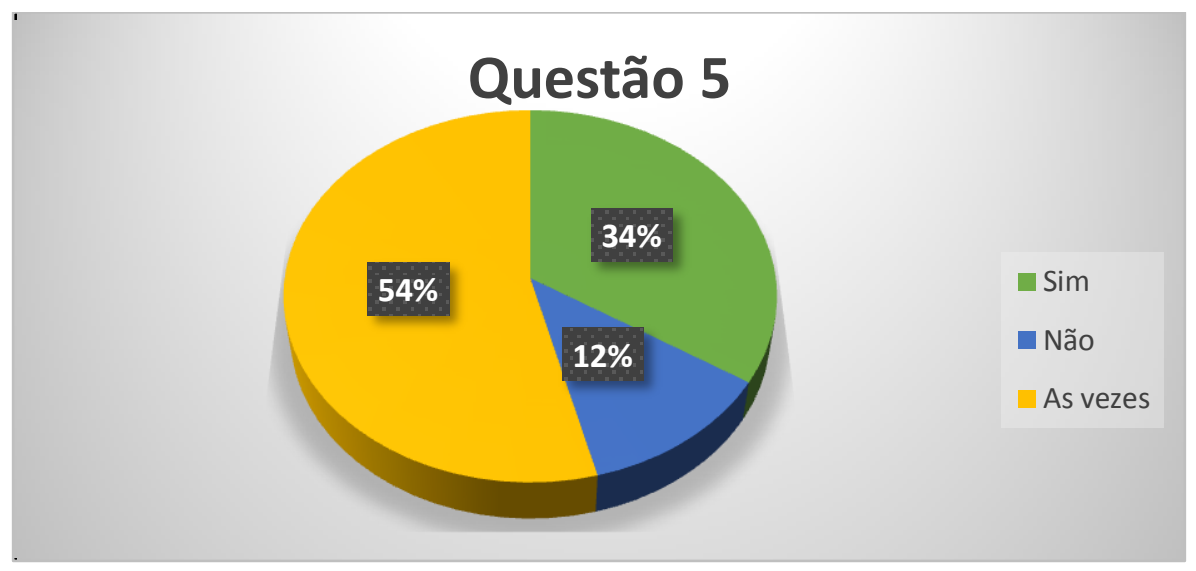

Fonte: Autores.

Na questão 6, o propósito foi de verificar se os consumidores pesquisados sabem o que é um Selo Ambiental, etc. Verificou-se que 52\% dos consumidores pesquisados sabem o que são Selos Ambientais, 24\% não sabem e 24\% já ouviram falar a respeito de Selos Ambientais.

Figura 17. Conhecimento dos selos ambientais. Barra do Garças-MT, 2017.

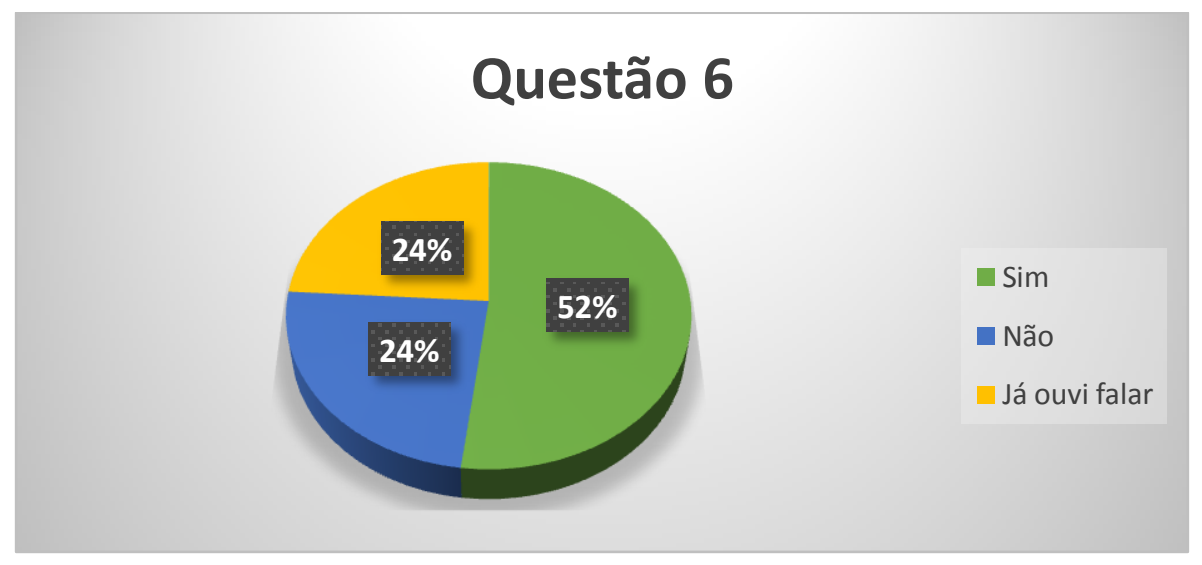

Fonte: Autores.

A fim de saber se os consumidores pesquisados sabem identificar os Selos Ambientais, foi elaborada a questão 7 e os resultados são descritos na Figura 18. Verificou-se que $50 \%$ dos consumidores pesquisados não sabem identificar um Selo Ambiental nas embalagens dos produtos, $46 \%$ conseguem fazer a identificação de um Selo Ambiental e 4\% não souberam responder.

Figura 18. Identificação dos selos ambientais. Barra do Garças-MT, 2017. 


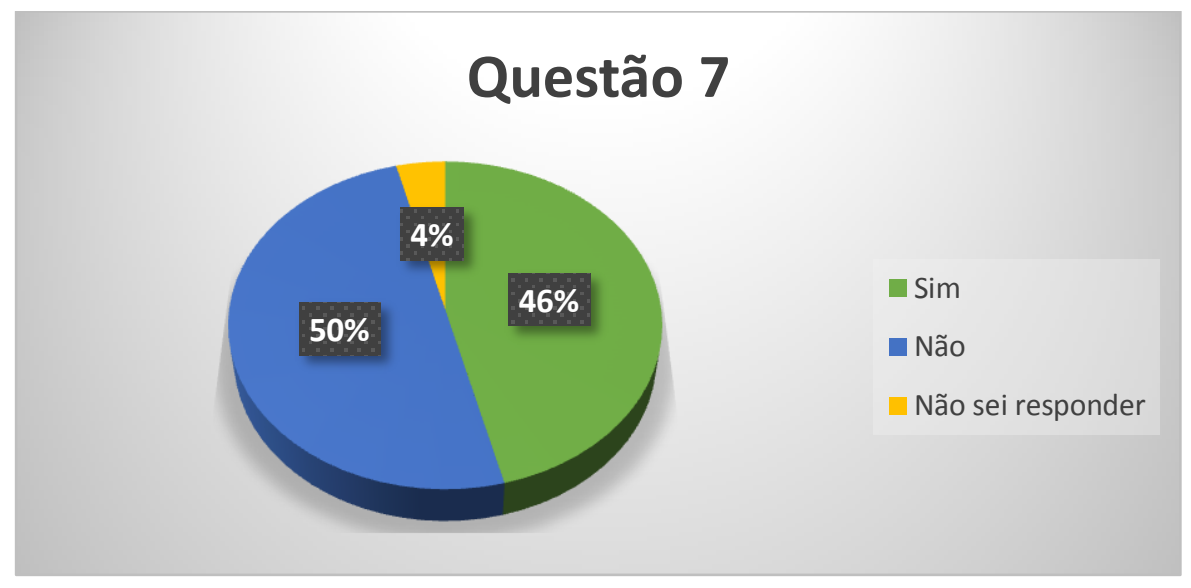

Fonte: Autores.

Na questão 8, analisou-se se a existência ou não dos Selos Ambientais nos produtos influenciam o poder de escolha dos consumidores por estes produtos. Verificou-se que para $70 \%$ dos consumidores pesquisados a existência dos Selos Ambientais não faz diferença no momento da escolha dos produtos que serão adquiridos e para $30 \%$ dos consumidores barragarcenses a existência destes Selos influenciam no poder de escolha por estes produtos (Figura 19).

Figura 19. Existência dos selos ambientais no processo de decisão de escolha dos consumidores. Barra do Garças-MT, 2017.

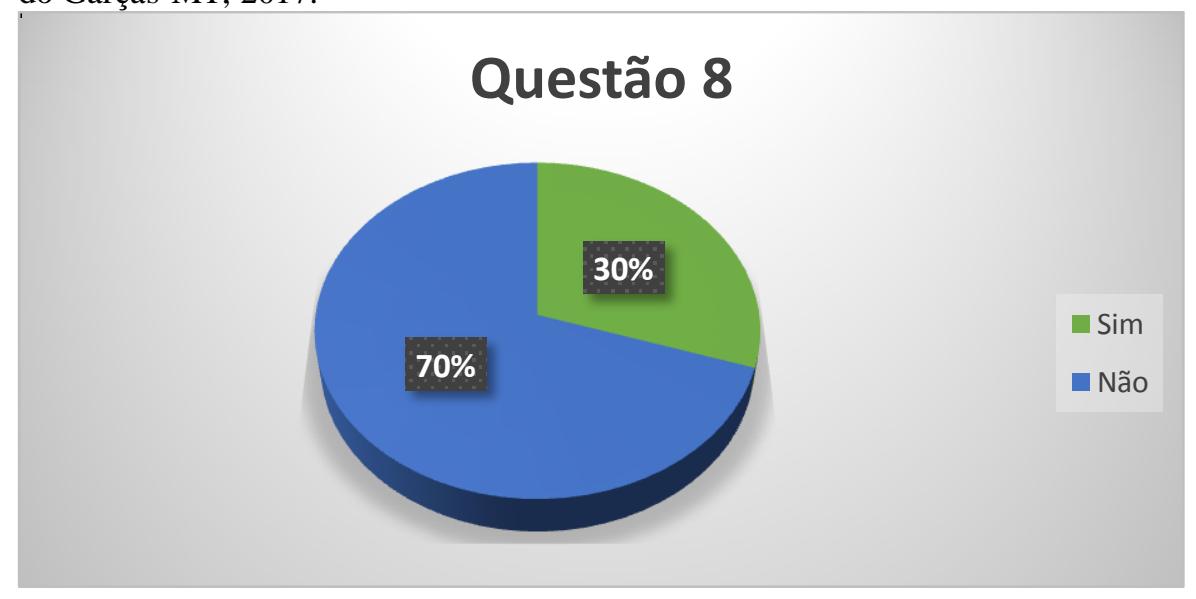

Fonte: Autores.

\section{CONSIDERAÇÕES FINAIS}

$\mathrm{O}$ que se considera a partir deste estudo é que os consumidores barragarcenses possuem pouca informação acerca dos Selos Ambientais, como mostra a Figura 17, em pode verificar-se que apenas $52 \%$ dos consumidores entrevistados sabem o que é um Selo Ambiental. Ocorre, também, falta de informação inerente ao processo produtivo, como pode 
ser observado na Figura 15, em que $41 \%$ dos consumidores entrevistados têm conhecimento de algum processo produtivo dos produtos consumidos.

A autorização para utilização dos Selos, ainda, é divulgada de forma tímida e confusa, o que pode ocasionar, entre os consumidores, comparações com Selos sem credibilidade. Assim, os principais critérios de compra do consumidor continuam sendo qualidade, preço e marca, com variações de acordo com as condições sociais e financeiras dos consumidores.

Uma pequena parcela de consumidores, com base na amostra levantada nesta pesquisa e verificada na Figura 18, tem aumentado suas preferências por produtos com qualidade ambiental. Nesse passo, é possível afirmar que apenas $46 \%$ destes consumidores sabem identificar os produtos que são produzidos de forma "ambientalmente correta". Isso mostra que as pessoas estão cada vez mais conscientes embora a falta de informação a respeito dos produtos auxilie a indecisão na hora da compra.

Dessa forma, o Selo Ambiental possui pouca relevância para os consumidores de Barra do Garças-MT, uma vez que o Figura 19 mostra que apenas 30\% dos consumidores entrevistados escolhem os produtos baseados na existência dos Selos Ambientais.

Faz-se necessário a utilização dos Selos Ambientais por meio de formas que levem, aos consumidores, informação clara, precisa e objetiva, como o marketing verde ou outras formas de divulgação por parte das empresas e dos fornecedores, com o intuito de que estas informações cheguem até o consumidor, visando o que será sustentável, logo, lucrativo para as empresas e conveniente para os clientes.

Conclui-se, então, que com os impasses causados pela falta de informação, percebese pouca clareza no tocante ao consumo consciente por parte dos consumidores barragarcenses, como mostra a Figura 19 e pode-se verificar que apenas $30 \%$ dos consumidores entrevistados utilizam como critério de escolha a existência de selos ambientais para adquirir produtos produzidos de forma ambientalmente amigável.

Assim sendo, chegou-se à resposta do problema proposto e verificou-se que a hipótese inicial estava correta, haja vista que os consumidores não tem informação suficiente para escolher os produtos de forma ambientalmente consciente. Ademais, o objetivo principal de levantar e analisar o grau de informação dos consumidores quanto a utilização de Selos Verde foi, devida e totalmente, alcançado, sendo possível concluir a pesquisa. Por último, pode-se afirmar que a metodologia utilizada foi adequada para que responder à problemática enfrentada na pesquisa e para se conseguisse o êxito na coleta e análise de dados levantados. 


\section{REFERÊNCIAS}

ABNT - Associação Brasileira de Normas Técnicas. NBR ISO 14020: rótulos e declarações ambientais, princípios gerais. Rio de Janeiro, 2002.

BARBIERI, J. C. Gestão ambiental empresarial: conceitos, modelos e instrumentos. 2. ed. São Paulo: Saraiva, 2008.

BARROS, J. D. S.; FREITAS, L. S. Rotulagem Ambiental: um estudo sobre os fatores de decisão de compra de produtos orgânicos. VII SEGET - Simpósio de Excelência em Gestão e Tecnologia - 2010. Disponível em: <https://www.aedb.br/seget/arquivos/artigos10/4 59_Rotulagem\%20versao\%20final\%20com\%20autores.pdf $>$. Acesso em: 23 setembro 2017. BIAZIN, C. C.; GODOY, A. M. G. O selo verde; uma nova exigência internacional para as organizações. Anais do XX Encontro Nacional de Engenharia da Produção e VI International Conference on Industrial Engineering and Operation Management. São Paulo, p.1-8, 30 de outubro a 01 de novembro de 2000 (publicado em CD). Disponível em: <http://www.abepro.org.br/biblioteca/ENEGEP2000_E0131.PDF>. Acesso em: 25 outubro 2017.

BIAZIN, C. C. Rotulagem Ambiental: um estudo comparativo entre programas. Dissertação apresentada ao Programa de Pós Graduação em Engenharia da Produção da Universidade Federal de Santa Catarina. Florianópolis, 2002.

BRASIL. Constituição da República Federativa do Brasil. Disponível em: <http://www.pla nalto.gov.br/ccivil_03/Constituicao/Constituicao.htm>. Acesso em: 23 novembro 2017. BRUNDTLAND, G. H. Nosso futuro comum: Comissão Mundial sobre Meio Ambiente e Desenvolvimento. Novembro 2006. 2. ed. Rio de Janeiro: Fundação Getúlio Vargas, 1991. CAMPOS, L.; KOHLRAUSCH, A. K.; SELIG, P. M. A influência dos rótulos ambientais no processo de compra de produtos orgânicos. Encontro Anual da ANPAD 28, 2004. Curitiba. EnANPAD, 2004. Disponível em: <http://www.anpad.org.br/admin/pdf/enanpad2004-gag0250.pdf>. Acesso em: 23 outubro 2017.

CANDEMIL, R. Mudanças de paradigmas para uma sociedade sustentável: um novo desafio para o Direito brasileiro? Monografia apresentado ao programa de Pós-graduação em Direito da Faculdade de Direito da UFRS. Porto Alegre, 2012.

DEUS, N. S.; FELIZOLA, M. P. M.; SILVA, C. E. O consumidor socioambiental e seu comportamento frente aos selos de produtos responsáveis. Revista Brasileira de Administração Científica. Aracaju, v. 1., p. 32-54, 2010.

EcoD - Selo ambiental da ABNT - Colibri. Disponível em: http://vivagreen.com.br/noticias/a bnt-lanca-selo-ecologico-inedito-para-eletroeletronicos/> Acesso em: 23 outubro 2017. EMBALAGEM SUSTENTÁVEL - Auto declaração, símbolos e logotipos. Disponível em: <http://embalagemsustentavel.com.br/2008/09/03/rotulagem-ambiental-i/> Acesso em: 25 outubro 2017.

FSC - Forest Stewardship Council - Selo ambiental. Disponível em: <https://pt.fsc.org/pt$\mathrm{pt} / \mathrm{mercados} /$ apoio-ao-uso-da-marca/como-utilizar-as-marcas-fsc $>$ Acesso em: 23 outubro 2017.

GRUETZMANN, P. Q. Direito de informação do consumidor e rotulagem de alimentos. Trabalho de Conclusão de Curso defendido na Universidade Regional do Noroeste do Estado do Rio Grande do Sul, UNIJUÍ em 2015. Santa Rosa-RS.

HOLT-GIMENEZ, Eric; ALTIERI, Miguel A.; ROSSET, Peter. Posição Política da Food First n. 12: Dez razões pelas quais a Aliança por uma Nova Revolução Verde, promovida 
pelas Fundações Rockfeller e Bill \& Melinda Gates, não resolverá os problemas de pobreza e fome na África Subsahariana. Oakland, Califórnia, EUA. 2006.

INMETRO - Instituto Nacional de Metrologia, Qualidade e Tecnologia. Disponível em: <http://www.inmetro.gov.br/consumidor/pbeSelo.asp>. Acesso em: 25 outubro 2017. IBD - Instituto Biodinâmico Selo de Qualidade Ambiental. Disponível em:

$<$ http://ibd.com.br/pt/Default.aspx> Acesso em: 25 outubro 2017.

KOHLRAUSCH, Aline Knopp. A Rotulagem Ambiental no Auxílio à Formação de Consumidores Conscientes. 2003. 153f. Dissertação (Mestrado em Engenharia de Produção) - Programa de Pós-graduação em Engenharia de produção, UFSC, Florianópolis.

MAPA, Ministério da Agricultura, pecuária e Abastecimento. Disponível em: <htt p://www.agricultura.gov.br/assuntos/inspecao/produtos-animal/sif $>$. Acesso em: 23 novembro 2017.

MARCONI, M. de A.; LAKATOS, E. M. Fundamentos de Metodologia Científica. 7. ed. São Paulo: Editora Atlas, 2010.

MOURA, A. M. M. O mecanismo de rotulagem ambiental: perspectivas de aplicação no Brasil. IPEA - Boletim Regional, urbano e ambiental. N.07, p.11-21, jan-jun 2013.

Disponível em: <http://www.ipea.gov.br/agencia/images/stories/PDFs/boletim_regional/1311 27_boletimregional7_cap2.pdf $>$. Acesso em: 26 outubro 2017.

NAKAHIRA, E.; MEDEIROS, G. A. Rotulagem Ambiental: o caso do setor de cosméticos. Trabalho de Conclusão do Curso de Gestão Empresarial apresentado na Faculdade de Tecnologia de Indaiatuba (FATEC-ID) do Centro de Ensino e Educação Tecnológico Paullo Souza. Espírito Santo do Pinhal, v. 6, n. 02, p. 544-563, mai/ago 2009.

OLIVEIRA, E. B.; CASTRO, A. C. F.; RAIMUNDINI, S. L.; STRUMIELLO, L. D. P. Desenvolvimento sustentável e produção mais limpa: estudo de caso em uma empresa do setor moveleiro. ConTexto, Porto Alegre, v. 9, n. 16, $2^{\circ}$ semestre 2009.

PREUSSLER, M. F.; MORAES, J. A. R.; VAZ, M.; LUZ, E.; NARA, E. O. B. Rotulagem Ambiental: Um estudo sobre a NBR 14020. XIII SIMPEP - Bauru, SP, Brasil, 06 a 08 de nov. de 2006.

PEREIRA, D. E. S.; BITTENCOURT, V. O direito à informação em matéria ambiental como pressuposto para a participação democrática e exercício da cidadania no Estado brasileiro.

Revista Jurídica - CCJ. ISSN 1982-4858. v. 17, n. 34, p. 79-96, jul./dez. 2013. Disponível em: <http://proxy.furb.br/ojs/index.php/juridica/article/view/4053>. Acesso em: 25 outubro 2017.

QUARTIM, E. Rotulagem ambiental. Publicado em 21 de setembro de 2011. Disponível em: <http://embalagemsustentavel.com.br/2011/09/21/4449/>. Acesso em: 21 novembro 2017. SABATUCCI, M. A. C. A percepção do consumidor das marcas de uma empresa com práticas sustentáveis: Empresa exemplo Unilever. Trabalho de Conclusão de Curso apresentado ao Curso de Administração do Instituto de Ciências Econômicas e Gerenciais da Pontifícia Universidade Católica de Minas Gerais. Belo Horizonte, 2012. p. 55-57.

TEIXEIRA, R. C. Marketing verde: fator de decisão na hora da compra. Trabalho de conclusão de curso apresentado a Universidade Cândido Mendes. Rio de Janeiro, 2009.

VIEIRA, S.; PERASSI, R. Gestão do design: a percepção da Imagem da Marca. Revista Estudos em Design (online). Rio de Janeiro: v. 21, n. 2 (2013), p. 01-21, ISSN 1983-196X. WESENDONCK, A. P.; ARAÚJO, R. Rotulagem Ambiental: um estudo sobre a criação de um selo verde para os laboratórios da UFPR. Trabalho de Conclusão de Curso apresentado a Universidade Federal do Paraná. p. 24. Curitiba, 2014.

\section{Modelo do questionário}

1) Com que frequência vai ao supermercado?

Revista de Direito e Sustentabilidade | e-ISSN: 2525-9687 | Salvador | v. 4 | n. 1 | p. 110 - 129 | Jan/Jun. 
( ) Semanalmente.

( ) Quinzenalmente.

( ) Mensalmente.

2) O seu critério de escolha dos produtos é pela marca, preço ou qualidade?

( ) Marca.

( ) Preço.

( ) Qualidade.

3) O que mais chama a sua atenção no rótulo do produto além do preço?

( ) Informações nutricionais.

( ) Símbolos.

( ) Não tem resposta.

4) Você tem conhecimento de alguma etapa do processo produtivo dos produtos de adquire?

( ) Sim.

( ) Não.

( ) Não sabe responder.

5) Você tem o hábito de ler as informações contidas nos rótulos das embalagens?

( ) Sim.

( ) Não.

( ) Às vezes.

6) Você sabe o que é um selo ambiental, selo verde, certificação ambiental, etc.?

( ) Sim.

( ) Não.

( ) Já ouviu falar.

7) Você sabe identificar na embalagem um selo ambiental?

( ) Sim.

( ) Não.

( ) Não sabe responder.

8) A existência ou não de selos ambientais fazem diferença no processo de compra?

( ) Sim.

( ) Não.

( ) Não sabe responder. 